\title{
Consumir el patrimonio: Kuelap y la sociedad local
}

\author{
Rommel Plasencia Soto \\ rplasencia@hotmail.com \\ Departamento de Antropología. UNMSM
}

\begin{abstract}
Resumen
Este artículo pretende resaltar la importancia monumental de Kuelap en el turismo de la región, y de cómo esta actividad puede convertirse en un eje importante para el desarrollo y la identidad cultural de las aldeas rurales del alto Utcubamba en el departamento de Amazonas.
\end{abstract}

Palabras clave: Etnoturismo, Desarrollo Local, Identidad Cultural, Chachapoyas.

\begin{abstract}
This article the monumental importance of Kuelap tries to highlight in him tourism of the region, and of since this activity can turn into important axle for the development and the cultural identity of the rural villages of the high place Utcubamba in to the department of Amazonas.
\end{abstract}

Keywords: Ethnic tourism, Local development, Cultural identity, Chachapoyas.

En un trabajo anterior (Plasencia, 2007), se proporcionó algunas nociones sobre la llamada antropología del turismo, poniendo como ejemplo el consumo de la cultura local (artesanías y psicotrópicos) por un número cada vez mayor de turistas en las comunidades Shipibo-Conibo de la región de Pucallpa. Se puso relevancia acerca del poder transculturizador de la actividad turística y de cómo esta se convierte en una fuente privilegiada de representación.

En este artículo, propondremos discutir algo más sobre el papel del turismo cultural y su efecto en aquellas sociedades que Kroeber llamó "parciales", es decir, en nuestro caso, de las comunidades rurales que están alrededor de un monumento cada vez más publicitado y visitado, como es la llamada fortaleza de Kuelap, del departamento de Amazonas, en la región nor-oriental del Perú. 


\section{Delineando una imagen-destino}

En primer lugar, debemos distinguir, básicamente, entre un recurso turístico que puede ser tangible o material (un paisaje o un monumento) del inmaterial o intangible (la cultura, la etnicidad o el folklore). Estos recursos turísticos -digamos en "bruto"- una vez planificados, diseñados y representados, se constituyen en productos turísticos listos para ser vendidos y consumidos. De este modo, tendríamos una imagen-destino, que sería el punto de llegada de los turistas. Llegan a ella, generalmente, a través de una agencia que compra el "paquete" a una gran corporación -ubicada generalmente en el hemisferio norte- que en definitiva son los que diseñan y guían el flujo turístico mundial ${ }^{1}$.

En cuanto a lugares de destino, actualmente, en América Latina, solo México ocupa un sitio entre los primeros 10 países (7mo lugar), después de Francia, España, USA, Italia, el Reino Unido y China.

En la vertiente de las Ciencias Sociales vinculadas al tema, se dice que el turismo es cultura, porque provoca un encuentro entre personas de distintas culturas (Smith, 1992), pero ampliando aún más el concepto, porque: fija una necesidad de adaptación a la cultura local. También, porque es en la relación contradictoria de aproximación (buscando otros espacios y otros tiempos) y de alejamiento (pues el visitante trae su bagaje cultural como referencia) que el turista "reconoce" y desarrolla su experiencia ${ }^{2}$.

No olvidemos que el turista compra, fundamentalmente, una experiencia, que se constituye mediante una mirada que es colectiva, configurada y pre-determinada (Urry, 2004). Además, la actividad turística es retráctil, cíclica, estacional y polimóvil ${ }^{3}$, y posee una actividad de "arrastre" de las actividades económicas. Es en este escenario complejo y disímil que se difumina la imagen del turismo reducido a la hotelería, la agencia de viajes y el restaurante; siendo necesario aclarar algunos conceptos claves para entender este artículo.

De este modo, los destinos turísticos pueden ser emergentes o consolidados (Chachapoyas vs. Cusco). Los turistas pueden ser potenciales (como los chinos), eventuales o habituales. Pero ellos caben ser clasificados. La tipología usual considera que un individuo coge maletas o su mochila y se aventura en este tipo de experiencia, de acuerdo a ciertos estímulos sociales anclados en visitas reales (la fidelidad), la publicidad y las experiencias de otros (se sostiene que el sistema boca/oreja es más eficaz que la agencia de viajes). De estímulos internos como el tipo de personalidad (aventurero o formal), el estilo de vida (observar aves no solo es caro, sino especializado) y los factores situacionales (las bajas en las tarifas aéreas, la sobreoferta de un destino o una guerra pueden reorientar el flujo).

\section{¿Un nuevo turismo?}

Se ha dicho que el viejo turismo "fordista", hijo del bienestar de la postguerra, empaquetado y estandarizado relacionado a las vacaciones y al ocio planificado, ha dado paso al "nuevo turismo" segmentado (se viaja hoy en periodos cortos, pero durante casi todo

1 El turismo también podría ser definido como un régimen de acumulación en base a la significación.

2 Sin embargo son los propios protagonistas nativos los que han planteado tres objeciones básicas: a) que no sean presentadas las culturas indígenas como exóticas, b) que no se promueva la atracción turística sin la consulta de los pueblos, y c) la prohibición de imágenes comerciales degradantes de las culturas anfitrionas.

3 Esto significa, por ejemplo, que las visitas se recuperan rápidamente luego de desastres sociales o naturales, como es el caso de Nueva York después del 11-S o de Indonesia. El caso inverso es Egipto, destino usual del turismo europeo que bajó bruscamente ante las actividades del fundamentalismo islámico. Es cíclica y estacional porque las visitas a un destino se relacionan con la dinámica de los países emisores o por los lugares de "moda". Por ejemplo, las temporadas "altas "en el Perú coinciden con las vacaciones europeas. Y polimóvil, porque el visitante combina la contemplación cultural con el ecoturismo o porque acopla el viaje guiado con el de iniciativa propia, incluso llega a destinos no planificados desde el incremento de los vuelos "last minute", rápidos y baratos. 
el año), flexible y hecho a pedido; abriendo aún más las posibilidades de crear nuevos destinos y la posibilidad de que nuevas sociedades se incorporen abruptamente a esta actividad.

Por segmentación se entiende también, la "especialización" de las visitas y los lugares, como por ejemplo el turismo de salud (incluido el termalismo), el religioso, de deportes, etc. Sin embargo, últimamente está en boga el llamado "turismo alternativo", el "turismo de aventura", el "turismo vivencial", el "turismo etno/ecoturísto" y el "turismo místico".

Todos ellos estarían insertados en lo que comúnmente se denomina el "turismo cultural" (Ballart y Tresserras, 2001).

Este tipo de visita turística - para contemplar una cultura/monumento- es heredera de la mirada romántica que -como sabemos- es una imagen deformada y deformante, relacionada con la idealización y la esencialización a-histórica pero que, curiosamente, echa mano de ella, pues la fija de forma inmanente, obviando las contradicciones y las turbulencias del contexto socio-histórico. Por ejemplo, el turismo en las ciudades puede oscilar entre la contemplación de lo más antiguo o lo más popular. El "turismo de arte", de "patrimonio" o de "lugares" son las variantes más usuales. Asimismo, la ciudad de París, no solo es el lugar vinculado a un tipo icónico (la torre Eiffel), sino, también, a un conjunto patrimonial que va del siglo XVIII (el Segundo Imperio) hasta el XIX. Sin embargo, en ella son obligatorias las visitas al Louvre, como al Centro Pompidou; la incursión de compras con las variedades del barrio latino. Esta dinámica sintetiza el arreglo simultáneo de las diversas miradas que se superponen cuando se visita una ciudad/destino.

El turismo rural, o de espacios naturales, puede dividirse, básicamente, en aquellas visitas a aldeas y comunidades rurales para participar de la experiencia del modo de vida campesino; de la contemplación ecoturística, que puede ser de interés general sobre un ecosistema determinado (un desierto, un bosque, unas montañas), de interés específico (aves, fauna silvestre, etc.) o el de contemplación de la naturaleza.

El problema de ambos tipos de turismo (el cultural y el de espacios naturales) es que pueden conducir al llamado "monocultivo turístico", es decir, cuando un recurso se convierte en la actividad estructurante y exclusiva, impidiendo o cancelando la diversificación económica, como ha sucedido en Bali.

La "marbellización" de la costa española nos puede servir también de ejemplo 4 . Sobrepoblación, contaminación visual e inmensos hoteles han dado como resultado el agotamiento del turismo de sol y playa, agravado por el surgimiento de nuevos destinos como el caribe y el sudeste asiático ${ }^{5}$. Ello ha exigido que España diversifique su potencial turístico hacia el ruralismo, el turismo de aventura y el de cultura, equilibrando de este modo, los espacios y los flujos de visitantes.

Otro fenómeno interesante, también extraído de la experiencia española, es el de la ciudad de Granada en la que la "musulmanización histórica" sí interesa, pues es atractiva; que es muy diferente a la "musulmanización social", que no interesa y es indeseable pues representa a una población de bajos ingresos y de inmigrantes ${ }^{6}$.

Cusco podría ser, también, un espacio para ejercitar este axioma, la población cusqueña de origen rural que habita en la ciudad de los incas es incómoda para el "centro histórico" y el "fetichismo monumental" de la ciudad".

4 Véase los interesantes trabajos de: Labarta, 1974 y Jurado, 1979.

5 Sheller, 2002.

6 Para el caso de Barcelona véase Reventós Gil 2007.

7 Caso que nos hace recordar la afirmación de Borges: "el indigenismo es una idea monumental cuyo protagonista es pobre". 


\section{El monumento}

Kuelap está ubicada en la provincia de Luya, departamento de Amazonas; pertenece al distrito de Tingo, creado en 1875, y está también equidistante del distrito de María.

Este impresionante conjunto de roca ubicada a $3200 \mathrm{msnm}$, entre relieves accidentados y bosques extensos, fue construido sobre un espolón, desde el cual se domina el paisaje de gran parte de la zona. Todo el complejo abarca una extensión, aproximada, de $5 \mathrm{Km}^{2}$. La Fortaleza, el sector más importante, se ubica en el extremo oeste del mismo.

Fue - para decirlo sencillamente- tardíamente puesto en circulación a mediados del siglo XX, para el consumo cultural y también sirvió para dotar de insumos a la identidad chachapoyana. Ya en 1537, Alonso de Alvarado, al fundar la ciudad de Chachapoyas, retuvo para sí entre otros, el repartimiento de Kuelap. En 1572, lo que Waldemar Espinoza (1967) denominó el "huno del norte" de la región, tenía por capital a la ciudad inca de Cochabamba y once ayllus, entre los que figuraban, Kuelap y Timpuy (Tingo?).

De todos modos, como han mencionado Espinoza (1967) y Schjellerup (2005), la región no constituyó una sociedad centralizada, sino, más bien, una suma de pequeños grupos dispersos (por ello se han registrado más de 200 lugares arqueológicos) alrededor de la cuenca del alto Utcubamba, con zonas productivas relativamente cercanas y compactas. Muy común en la economía agrícola de la región (Brush, 1977), ofreciendo un notorio declive ambiental, que hizo necesario el intercambio y de formas generalizadas de reciprocidad.

Pasando por alto el hecho de que la presencia de mitmas más importantes en el periodo inca fue de los huancas o que la primera fundación española de Chachapoyas fue en el pueblo de La Jalca, camino a Leymebamba y Balsas (la importante ruta hacia Cajamarca por el río Marañón).

Debe de tomarse en 1843 la fecha en donde se inicia, en cierto modo, el interés por este monumento; cuando un juez cajamarquino hizo un reporte sobre Kuelap, al asistir a una diligencia de rutina. Ya posteriormente, aventureros y "exploradores", como Flornoy y Savoy, la darían a conocer, estableciendo las primeras rutas para las visitas turísticas. Sin embargo, la investigación arqueológica no fue descuidada, aunque fue siempre puntual como los estudios de Reichlen, Horkheimer y Ruiz Estrada.

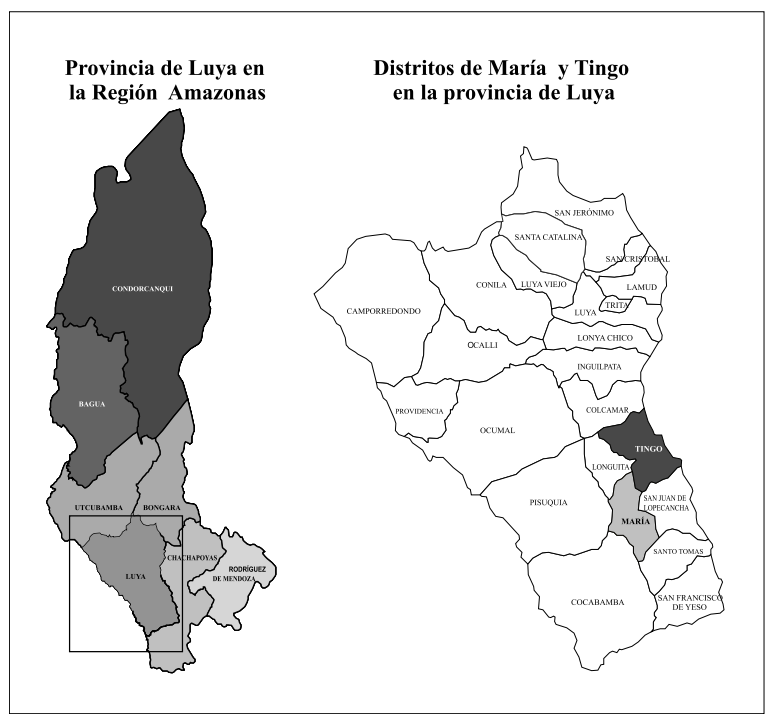




\section{El producto Kuelap}

A fines del 2001, se emite una resolución suprema en que la Comisión de Promoción de de la Inversión Privada (COPRI) entregaba en concesión al sector privado el proyecto "Complejo Hotelero Playas del Norte" y la "Fortaleza Kuelap". El ministro de industria y turismo de la época era Raúl Diez Canseco Terry, quien parece fue el promotor y principal interesado en esas concesiones. Asesores muy cercanos al entonces ministro eran Gonzalo Cillóniz, propietario de la Hacienda San José en Chincha, y el arquitecto Ramiro Salas, viceministro de Turismo, quien tenía especial interés - quizás por encargo del ministro-por Kuelap. En este último sitio, se había proyectado construir un helipuerto y, posteriormente, construir un teleférico. La movilización de la población, tanto en Tumbes como en Kuelap, agravada después con la salida intempestiva del ministro, impidió el inicio del proyecto.

Sin embargo, había no solo intereses empresariales, sino, también, una especial concepción sobre el desarrollo turístico y el papel de las comunidades locales. Ha sido usual, en primer lugar, poner a "gente bien" en la gestión pública del turismo ${ }^{8}$. Como si una inconfesable pulsión nacional ordenase que para ser interlocutor ante el extranjero (el blanco deseado), se tenga que pasar por gente parecida a ella, al igual que en la diplomacia, en nuestro país pareciese vergonzoso que un peruano "nativo" (negro/cholo/indio) pudiese representarnos en la actividad turística. En segundo lugar, a diferencia de países como Colombia, México o Brasil, la respon-sabilidad del manejo estatal del turismo en el Perú siempre ha recaído en empresarios, es decir, la empresa privada era vista cómo la más indicada - por el gobiernopara manejar esta importante franja de nuestra economía. Y en tercer lugar, ese tipo de funcionarios que confunden la administración pública con una agencia de turismo, ha pensado poco en incorporar en sus proyectos a la población local, que no solo puede ser propietaria de ese patrimonio o monumento, sino que también tiene que ver con el juego de un conjunto de factores relacionados con la identidad local o regional. Y cuando se han inventado historias para el turismo cultural, se ha obviado nuevamente su participación.

No olvidemos que el patrimonio es un elemento importante del desarrollo del nacionalismo cultural. Resaltar no sólo el monumento, sino, también, la sociedad local, es importante no sólo para su mejoramiento económico: "la universalización de la contemplación turística ha hecho que la mayoría de otros lugares refuercen la diferencia a menudo por medio del descubrimiento de estilos locales vernaculares que transmiten historias particulares" (Urry, 2004:127).

Narváez (2001) plantea, en ese sentido, que de los cuatro principios útiles para el desarrollo turístico (precio, producto, plaza y promoción); son el producto y la plaza quizás los más importantes.

De este modo, Kuelap posee las características de calidad y de monumento "único" y homologable a la vez con Macchu Picchu. Respecto a la plaza (el lugar), el transporte, el clima y la accesibilidad, son los indicadores importantes a ser considerados. No está por demás decir que llegar a Chachapoyas es difícil, aunque las visitas se han ido incrementando como veremos más adelante. Este incremento del flujo, además, se inserta con el "boom de hallazgos arqueológicos" de Lambayeque, su departamento vecino.

El Kuelap intangible, de paisaje diverso y geografía atractiva, se corresponde con el turista exigente y afín a la aventura.

El único problema es cómo hacer que no solo el desarrollo de Kuelap se retruque en las comunidades vecinas, sino que su población sea sujeto activo del turismo rural, explotando sus recursos locales. Recursos que otros documentos ya han detallado: su arquitectura

8 Durante el gobierno militar de los 70, la Marina de Guerra era la encargada de ese portafolio. 
local, su gastronomía, su artesanía y, sobre todo, el conocimiento de la diversidad biológica y productiva de la zona (Trujillo, 2004; Municipio de María, 2006).

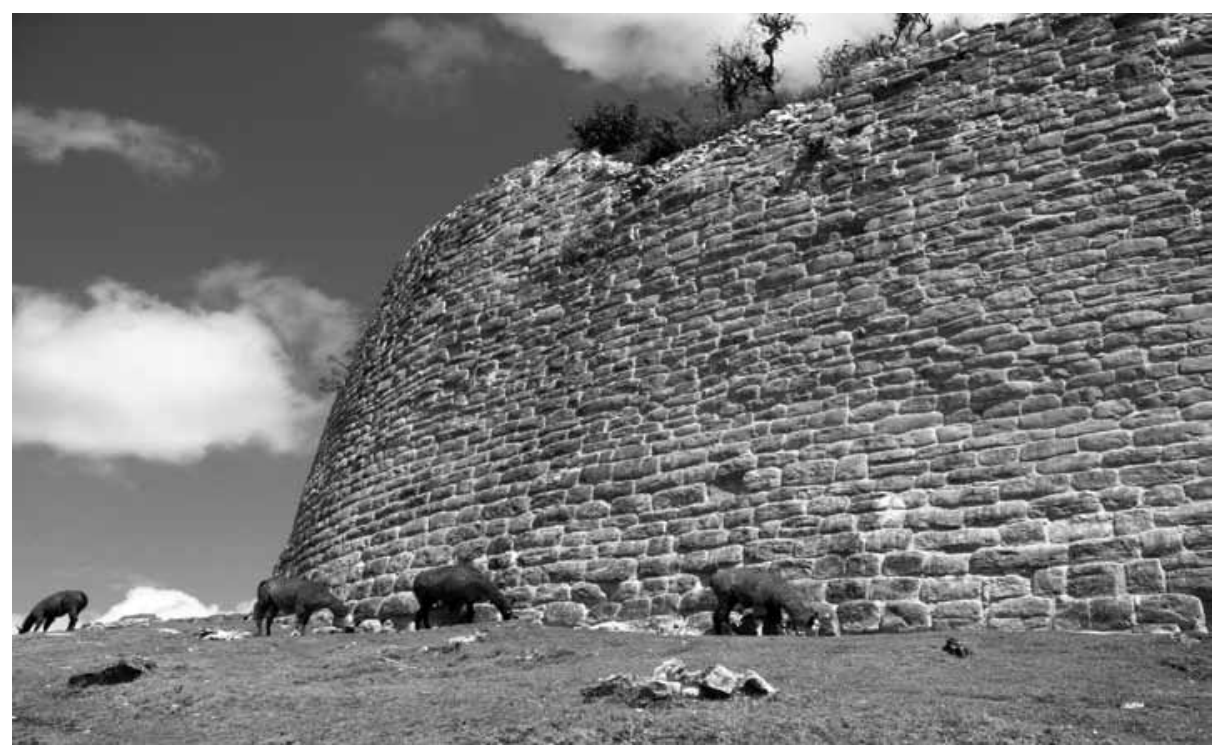

\section{La sociedad local}

Los distritos de Tingo y María están situadas en la margen izquierda del río Utcubamba, en la provincia de Luya, a una cota de $2000 \mathrm{~m}$ (figura 1). Ambas comunidades abarcan 180 $\mathrm{km}^{2}$, aproximadamente. Con San Juan de Lopecancha, Colcamar y Lónguita, conforman una suerte de micro región en la que el control "multicíclico" de diversas franjas productivas es su principal característica.

Las "playas", fondos de valle y montes ribereños, productora de algunos frutales y caña de azúcar destinada al consumo local, son sucedidas por la zona agrícola de las laderas intermedias; $y$, finalmente, la jalca, laderas onduladas y seno de divisorias del Utcubamba, donde pastorea el ganado vacuno.

Tingo, creada en 1875, fue, en cierto modo, destruida por un aluvión en 1993. Por ello, la población fue reubicada en una pequeña planicie de la parte alta, donde se planificó y urbanizó la actual capital del distrito, que hoy se denomina Tingo Nuevo.

Tingo viejo, entonces, situado al borde de la carretera que conduce a Leymebamba, y testigo también del tráfico fluido hacia Chachapoyas, tiene en Yerbabuena una importante feria que articula al campesino de la zona con el mercado regional.

Hasta la reforma agraria de 1969, existían tres haciendas en Tingo: Kuelap, San Miguel de Velapata y Huamantianga. Hoy, existe una acentuada migración hacia Chiclayo y algunas ciudades medianas del departamento de San Martín, como: Nueva Cajamarca, Moyabamba y Tarapoto.

Los pequeños comerciantes de la zona, proceden generalmente de Celendín, de donde las migraciones a las tierras bajas y subtropicales, se han debido a las crisis de la agricultura familiar campesina.

En promedio, un comunero suele tener entre una a cinco hectáreas, divididas en distintas parcelas, aunque las mejores tierras son de conducción privada, es decir, se encuentran 


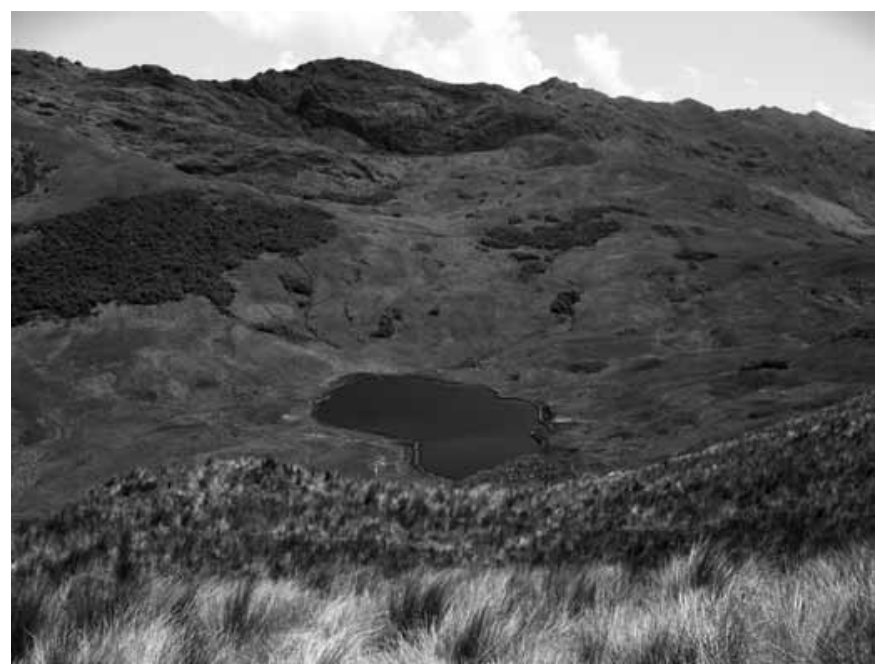

en posesión de un número reducido de agricultores que han ido adquiriendo tierras a través de la compra a los propietarios de las antiguas haciendas.

En estas ex haciendas se encuentran las mejoras tierras del distrito, pues está asociada a abundantes pastos naturales. En definitiva, Tingo posee 144 alumnos en el nivel inicial y primario y 94 en su colegio secundario "Jorge Basadre".

María, en cambio, es un distrito más joven, creado en 1962; está conformada por tres barrios y tres anexos (Pisango, Cuchapampa y Mangalpa). Tiene, aproximadamente, 900 pobladores, de los cuales más de la mitad habita el casco "urbano". Posee 123 alumnos de educación inicial y primaria, y, además, 134 en el colegio secundario "Horacio Zevallos Gámez"; en total, son 15 los docentes en la localidad.

Marina López López (56 años, natural de Yoque del distrito de Pisuquía y residente en María) nos ha dado su versión de la leyenda más conocida de la zona:

"Una pareja de enamorados de Choctamal ante la oposición de sus padres ante
la relación, deciden "zafarse" (escaparse), y pasan por la cordillera de Shundor,
el Juan Changalí en su huida siempre iba adelante y la Juana Cuella se retrasaba
constantemente, al pasar la cordillera Juana Cuella se encanta, el Juan Changalí
pensando que su compañera la seguía, avanzaba y avanzaba; encantándose también
y formando la laguna de Changalí. A partir de ahí, la laguna de Cuchacuella estaba
"encantada", comía gente y animales, hasta que en el curso de los años la fueron
"amansando" con ajos. Es también allí donde los curanderos "conversan" con los
"infieles" para curar, como lo hacía el Sr. Juan Arista, connotado curandero de
María". En el relato, se pueden percibir los siguientes principios:

- Se traduce la oposición y el tránsito de la naturaleza (percibida como el espacio bravo y salvaje) hacia la cultura (la actividad agropecuaria).

- El doblegamiento del espacio "salvaje" se hace mediante los ajos (quizás herencia de la farmacopea rural europea) o el "conversatorio" con los "infieles" (gentiles pre-cristianos), que revelan una superposición ideológica muy común en la sierra peruana.

- Las lagunas “encantadas” revelan un principio básico del pensamiento andino: otorgan fuerza y poder, pero también son peligrosas, pues la jalca es un espacio no señalizado, socializado $\mathrm{u}$ organizado.

- Juan Changalí y Juana Cuella representan la dualidad macho/hembra. Al ir adelante el novio, podría enfatizar la primacía masculina, muy común en la organización familiar de la sierra norte. Por tal motivo, quizá el distrito de María tenga una connotación femenina. 


\section{Detrás de la postal}

El Cuadro N. ${ }^{\circ} 1$ nos ofrece la evolución del flujo turístico hacia el departamento de Amazonas hasta el año 2001. La abrupta baja en ese año se debió sin duda alguna a la interrupción de los vuelos aéreos a raíz de un accidente aeronáutico.

\section{Cuadro N. ${ }^{\circ} 1$.}

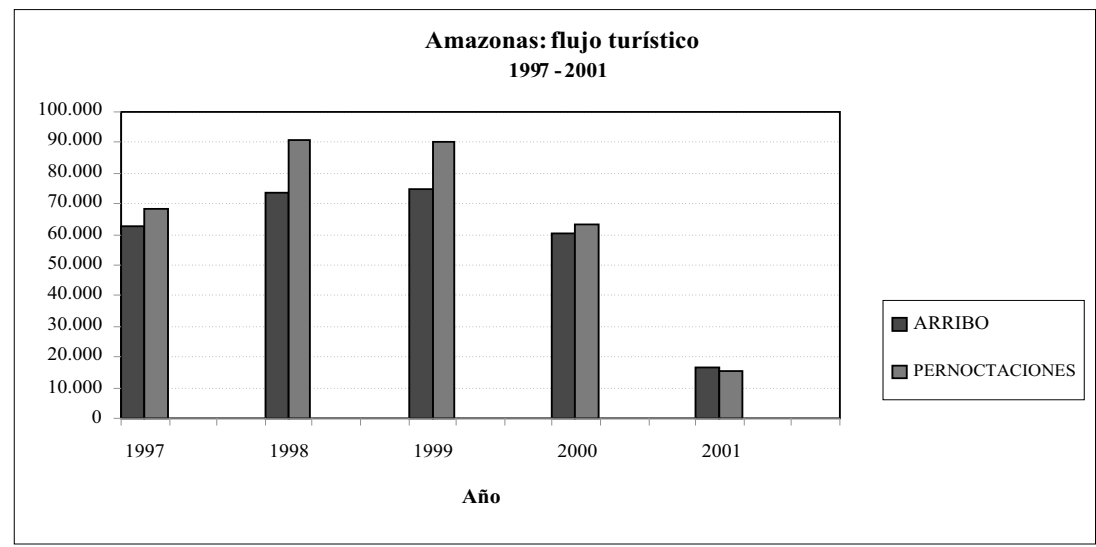

Aunque después hubo una rápida recuperación, debemos reconocer que el departamento conjuga una variedad importante de recursos turísticos en que la atracción monumental y arqueológica es la más importante.

Aparte de Kuelap, son Revash, Carajía y Leymebamba, sitios pre-hispánicos dignos de ser visitados, conjuntamente con La Jalca y la misma ciudad de Chachapoyas que muestra la ascendencia que tuvieron los españoles en la región.

Cuadro N. ${ }^{\circ}$ 2. Amazonas: establecimientos de hospedaje, agencias de viaje, restaurantes, discotecas y videos pub registrados, 2006 - 2007.

\begin{tabular}{|c|c|c|c|c|c|c|c|c|c|c|c|c|c|c|}
\hline \multirow{2}{*}{ Establecimientos } & \multicolumn{12}{|c|}{2006} & \multicolumn{2}{|c|}{2007} \\
\hline & Ene. & Feb. & Mar. & Abr. & May. & Jun. & Jul. & Ago. & Set. & Oct. & Nov. & Dic. & Ene. & Feb. \\
\hline $\begin{array}{l}\text { Establecimientos de } \\
\text { Hospedaje }\end{array}$ & 70 & 70 & 78 & 82 & 88 & 88 & 88 & 88 & 88 & 88 & 88 & 88 & 88 & 88 \\
\hline Agencias de Viaje & 12 & 12 & 14 & 15 & 15 & 17 & 18 & 19 & 19 & 22 & 22 & 22 & 23 & 23 \\
\hline Restaurantes & 317 & 318 & 321 & 323 & 323 & 323 & 323 & 323 & 323 & 325 & 325 & 325 & 325 & 325 \\
\hline Discotecas & 32 & 32 & 32 & 32 & 32 & 32 & 32 & 32 & 32 & 32 & 32 & 32 & 32 & 32 \\
\hline Video Pub & 23 & 23 & 23 & 23 & 23 & 23 & 23 & 25 & 25 & 25 & 25 & 25 & 25 & 25 \\
\hline
\end{tabular}

Fuente: Dirección Regional de Comercio Exterior y Turismo - Amazonas.

Elaboración propia. 
La infraestructura de alojamiento en Amazonas como lo reflejan los cuadros 5 y 7 , no es desdeñable, pero tampoco es la óptima. Es muy disímil el universo hotelero y de hospedajes.

Existen 24 establecimientos adecuados de 2 estrellas con, aproximadamente, 755 plazas-cama, y 101 establecimientos en todo el departamento, de los cuales solo 6 superan las 40 habitaciones.

Sin embargo, el número y la calidad han ido creciendo en función del aumento del flujo, aunque lo que nos preocupa aquí es la calidad y la gestión de los hospedajes rurales en manos de la población local.

En María, paso obligado hacia Kuelap, hay, actualmente, nueve centros de alojamientos (Huishimal, El Inguil, Shangalí, El Torreón, Cushacuella, El Mirador, Mechita, El Lirio y Kuelap). Muchos de ellos han sido financiados y promovidos por Cáritas dentro de los objetivos de un proyecto gubernamental (Promartuc).

Sin embargo, las agencias que operan en Chachapoyas hacen recorridos rápidos hacia el monumento, sin detenerse en ambas jurisdicciones.

Esta omisión aunada a la falta de publicidad, muestran la incapacidad del Estado para coordinar con la "iniciativa privada" del turismo.

Cuadro N. ${ }^{\circ}$ 3. Amazonas: número de turistas nacionales y extranjeros que visitaron la fortaleza de Kuélap, 2001-2007.

\begin{tabular}{l|l|l|l|l|l|l|l|l}
\hline \multirow{2}{*}{ Turistas según origen } & \multicolumn{7}{c|}{ Año } & \multirow{2}{*}{ Total } \\
\cline { 2 - 8 } & 2001 & 2002 & 2003 & 2004 & 2005 & 2006 & 2007 & \\
\hline Total & 7,267 & 8,937 & 9,816 & 10,371 & 9,472 & 11,981 & 1,400 & 59,244 \\
Nacionales & 5,877 & 7,471 & 8,129 & 8,688 & 7,222 & 8,682 & 1,096 & 47,165 \\
Extranjeros & 1,390 & 1,466 & 1,687 & 1,683 & 2,250 & 3,299 & 304 & 12,079 \\
\hline
\end{tabular}

Nota: En el año 2007, se consignan los meses de enero y febrero solamente.

Fuente: Filial INC - Amazonas.

Elaboración propia.

A pesar de ello, Kuelap sigue siendo el modelo paradigmático de Amazonas, que algunos sectores desean replicar lo sucedido con Macchu Picchu. Con el gobierno de Toledo, se quiso imponer lo que algunos periodistas norteños motejaron de "turismo chatarra" . Esto es, la "burbuja turística" para visitantes de mayor edad, de mayor capacidad adquisitiva, pero inactiva; trasladada y alojada en complejos controlados por grandes empresas, quizás transnacionales, y en que los políticos/empresarios operarían como intermediarios. Y para las comunidades rurales nada.

Es como si Túnez o Marruecos quisieran imitar el desarrollo turístico de sol y playa que implementó España en los años 60, desconociendo que no solo albergan sociedades con mucha población pobre y enquistadas en desigualdades, sino que ese modelo agotaría los recursos, colmándolos y haciéndolos a mediano plazo, inviables e insostenibles.

9 ¿Kuelap Fried Chicken? se preguntaba la periodista Roxana Cuba, aludiendo al inusitado interés del ministro Raúl Diez Canseco. Puede verse también "Lundero", publicación cultural de La Industria de Chiclayo, marzo de 2002, en donde da cuenta de la tensa reunión entre el ministro y la población vecina a Kuelap, por la misma época. 
Sin embargo, no ha pasado mucho tiempo para que el nuevo gobierno haya tratado de imponer un modelo que va en la vía vedada, y que, por el momento, ha ocasionado paros de la población cusqueña -más sensible al tema- y la oposición de los profesionales ${ }^{10}$.

La crítica a Kuelap, en su momento, como ahora lo son los destinados al patrimonio histórico y natural en general, ha obligado a revisar modelos. Los menos sensibles son -por supuesto- los "empresarios", como aquel francés dueño del Hotel "El Arqueólogo", de 3 estrellas, que para ampliarlo, derribó una pared inca. Hoy camina próspero y diligente por las viejas calles cusqueñas.

En general, una rápida mirada de la demanda turística nos hace detenernos en el número de turistas que visitan la zona. No olvidemos, además, que el número de turistas que llegan a la zona debe corresponderse con la dimensión de la población anfitriona (rural y dispersa) y con la escala del objeto (monumento) que se contempla.

El asunto es como desplazarnos del "fetichismo patrimonial" al desarrollo horizontal del turismo rural comunitario. En un "árbol de problemas" que incluimos en el anexo del artículo, se presentan algunas dificultades que enfrenta el turismo rural y que a su vez, reproduce otras.

Para finalizar, en el Cuadro N. ${ }^{\circ} 4$ se observa el nadir de las visitas a Kuelap; cruzando la información con las que ofrecen los hoteles de Tingo viejo, podemos deducir que los meses de estiaje en la zona coincide con las vacaciones europeas. Lo cual ofrece una oportunidad para planificar las inversiones y el equipamiento, otorgando un papel activo a la población rural que por ese mismo periodo, pasa por un "desempleo estacional".

Es cuestión de una adecuada propuesta si parten a buscar otras opciones laborales fuera de la región o hacen del turismo un eficaz medio de vida.

Cuadro N. ${ }^{\circ} 4$

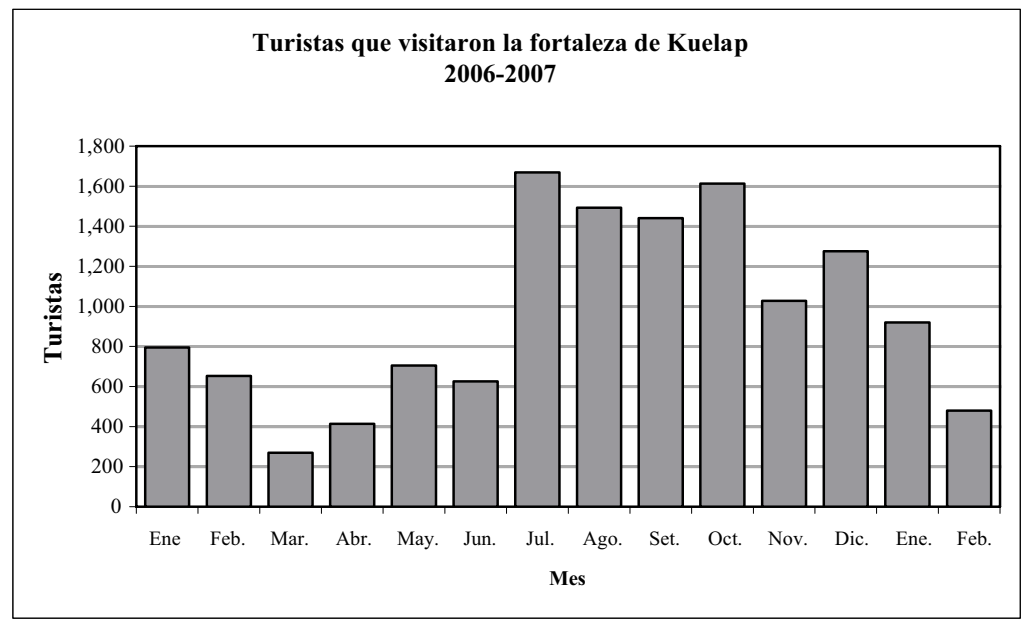

10 La ley N. ${ }^{\circ} 29164$, promulgada en diciembre de 2007, tendría como meta promover la inversión privada en lugares adyacentes a los centros históricos de interés turístico. Sin embargo, existirían tres principales objeciones: solo autorizar establecimientos de 4 estrellas deja de lado toda iniciativa local, no específica que se entiende por "áreas adyacentes", pues colisiona con las labores de investigación y restauración arqueológica. Finalmente, la filosofía de la ley contradice los propios lineamientos del estado sobre el turismo rural comunitario, destinados a fortalecer los recursos nativos. 


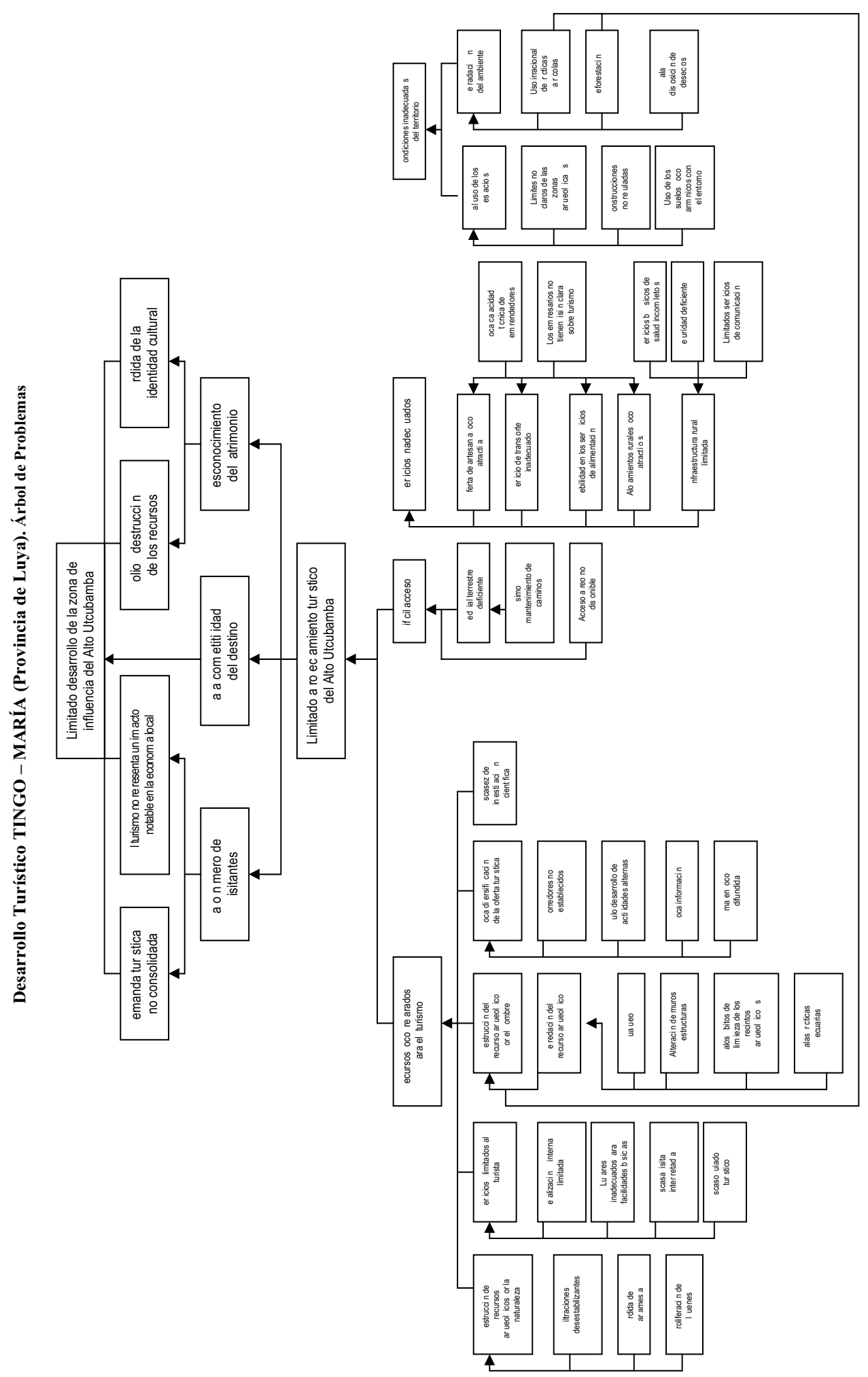




\section{Algunas conclusiones}

- Los distritos de Tingo y María poseen los rangos más bajos de la estructura demográfica del departamento (menos de mil habitantes).

- Sin embargo, en Tingo la antigua población estuvo nucleada en torno de la carretera Chachapoyas-Leymebamba. La nueva población de Tingo también lo está, pues fue planificada.

- La población de María es más dispersa, lo cual traduce una mayor vocación agropecuaria y de diversidad de recursos.

- Tingo está más articulada al mercado regional, es más antigua y fue sede de los poderes locales de la región.

- En el sector agropecuario, ambos distritos comparten características: minifundio, bajos niveles de productividad y ausencia de agentes gubernamentales de apoyo (cuadros 5 y 6 ).

- La explotación de los recursos locales es en beneficio extra-local.

- Existe una rápida pérdida de la arquitectura tradicional sobre todo, en Tingo.

- Existe una limitada capacidad de oferta turística en ambas poblaciones.

- El turismo regional excluye a las comunidades a lo largo del corredor ChachapoyasKuelap.

Cuadro N. ${ }^{\circ}$ 5. Departamento de Amazonas: nuevo mapa de pobreza provincial de FONCODES, 2006.

\begin{tabular}{|c|c|c|c|c|c|c|c|c|c|}
\hline \multirow{2}{*}{ Provincia } & \multirow{2}{*}{$\begin{array}{l}\text { Población } \\
2005\end{array}$} & \multirow{2}{*}{$\begin{array}{l}\text { Índice de } \\
\text { carencias al }\end{array}$} & \multirow{2}{*}{$\begin{array}{l}\text { Quintil del } \\
\text { indice de } \\
\text { carencias b/ }\end{array}$} & \multicolumn{3}{|c|}{ \% De la población sin: } & \multirow{2}{*}{$\begin{array}{c}\text { Tasa } \\
\text { analfab. } \\
\text { Mujeres }\end{array}$} & \multirow{2}{*}{$\begin{array}{c}\% \text { Niños } \\
\text { de } \\
0-12 \text { años }\end{array}$} & \multirow{2}{*}{$\begin{array}{c}\text { Tasa de } \\
\text { desnutric. } \\
1999\end{array}$} \\
\hline & & & & Agua & $\begin{array}{l}\text { Desag.I } \\
\text { Letrin. }\end{array}$ & Electric. & & & \\
\hline Amazonas & 389,700 & 0.7816 & 1 & $37 \%$ & $17 \%$ & $58 \%$ & $19 \%$ & $34 \%$ & $43 \%$ \\
\hline Chachapoyas & 49,573 & 0.203 & 2 & $26 \%$ & $15 \%$ & $32 \%$ & $12 \%$ & $28 \%$ & $31 \%$ \\
\hline Bagua & 74,256 & 0.5317 & 2 & $41 \%$ & $7 \%$ & $56 \%$ & $18 \%$ & $34 \%$ & $46 \%$ \\
\hline Bongara & 24,977 & 0.3364 & 2 & $23 \%$ & $19 \%$ & $46 \%$ & $15 \%$ & $31 \%$ & $35 \%$ \\
\hline Condorcanqui & 46,925 & 0.9731 & 1 & $77 \%$ & $30 \%$ & $94 \%$ & $30 \%$ & $45 \%$ & $61 \%$ \\
\hline Luya & 49,733 & 0.5193 & 2 & $22 \%$ & $16 \%$ & $55 \%$ & $23 \%$ & $33 \%$ & $48 \%$ \\
\hline $\begin{array}{l}\text { Rodríguez de } \\
\text { Mendoza }\end{array}$ & 25,869 & 0.3446 & 2 & $33 \%$ & $40 \%$ & $58 \%$ & $12 \%$ & $28 \%$ & $25 \%$ \\
\hline Utcubamba & 118,367 & 0.502 & 2 & $35 \%$ & $16 \%$ & $59 \%$ & $20 \%$ & $33 \%$ & $39 \%$ \\
\hline
\end{tabular}

a/ Es un valor entre 0 y 1 . Este índice es obtenido mediante el análisis factorial por el método de las componentes principales.

b/ Quintiles ponderados por la población, donde el 1=Más pobre y el 5=Menos pobre.

Fuente: Foncodes.

Elaboración propia. 
Cuadro N. ${ }^{\circ}$ 6. Provincia de Luya: nuevo mapa de pobreza provincial de FONCODES, 2006.

\begin{tabular}{|c|c|c|c|c|c|c|c|c|c|}
\hline \multirow{2}{*}{ Provincia } & \multirow{2}{*}{$\begin{array}{l}\text { Población } \\
2005\end{array}$} & \multirow{2}{*}{$\begin{array}{l}\text { Índice de } \\
\text { carencias a/ }\end{array}$} & \multirow{2}{*}{$\begin{array}{l}\text { Quintil del } \\
\text { índice de } \\
\text { carencias } \\
\text { b/ }\end{array}$} & \multicolumn{3}{|c|}{$\%$ de la población sin: } & \multirow{2}{*}{$\begin{array}{c}\text { Tasa } \\
\text { analfab. } \\
\text { Mujeres }\end{array}$} & \multirow{2}{*}{$\begin{array}{c}\% \text { niños de } \\
0-12 \text { años }\end{array}$} & \multirow{2}{*}{$\begin{array}{c}\text { Tasa } \\
\text { de } \\
\text { desnu } \\
\text { tric. } \\
1999\end{array}$} \\
\hline & & & & Agua & $\begin{array}{l}\text { Desag./ } \\
\text { Letrin. }\end{array}$ & $\begin{array}{c}\text { Elec- } \\
\text { tric. }\end{array}$ & & & \\
\hline Luya & 49,733 & 0.5193 & 2 & $22 \%$ & $16 \%$ & $55 \%$ & $23 \%$ & $33 \%$ & $48 \%$ \\
\hline Lamud & 2,550 & 0.198587306 & 2 & $15 \%$ & $13 \%$ & $31 \%$ & $22 \%$ & $28 \%$ & $25 \%$ \\
\hline Camporredondo & 5,765 & 0.447382772 & 2 & $9 \%$ & $6 \%$ & $27 \%$ & $26 \%$ & $35 \%$ & $51 \%$ \\
\hline Cocabamba & 2,133 & 0.790831403 & 1 & $65 \%$ & $43 \%$ & $77 \%$ & $21 \%$ & $34 \%$ & $56 \%$ \\
\hline Colcamar & 2,560 & 0.520801328 & 2 & $16 \%$ & $10 \%$ & $51 \%$ & $27 \%$ & $30 \%$ & $60 \%$ \\
\hline Conila & 2,114 & 0.489850268 & 2 & $46 \%$ & $18 \%$ & $31 \%$ & $27 \%$ & $30 \%$ & $50 \%$ \\
\hline Inguilpata & 707 & 0.168394141 & 2 & $17 \%$ & $27 \%$ & $36 \%$ & $17 \%$ & $22 \%$ & $31 \%$ \\
\hline Longuita & 948 & 0.47900512 & 2 & $51 \%$ & $5 \%$ & $30 \%$ & $24 \%$ & $33 \%$ & $47 \%$ \\
\hline Lonya Chico & 1,147 & 0.365572802 & 2 & $10 \%$ & $15 \%$ & $25 \%$ & $26 \%$ & $30 \%$ & $48 \%$ \\
\hline Luya & 4,330 & 0.40068387 & 2 & $22 \%$ & $14 \%$ & $59 \%$ & $21 \%$ & $30 \%$ & $38 \%$ \\
\hline Luya Viejo & 415 & 0.727694368 & 1 & $99 \%$ & $5 \%$ & $14 \%$ & $32 \%$ & $37 \%$ & $58 \%$ \\
\hline María & 945 & 0.26489597 & 2 & $11 \%$ & $0 \%$ & $16 \%$ & $17 \%$ & $30 \%$ & $53 \%$ \\
\hline Ocalli & 3,729 & 0.28085702 & 2 & $6 \%$ & $7 \%$ & $27 \%$ & $17 \%$ & $31 \%$ & $46 \%$ \\
\hline Ocumal & 3,846 & 0.571847252 & 2 & $2 \%$ & $4 \%$ & $77 \%$ & $17 \%$ & $37 \%$ & $54 \%$ \\
\hline Pisuquia & 5,823 & 0.780535366 & 1 & $46 \%$ & $36 \%$ & $91 \%$ & $23 \%$ & $37 \%$ & $48 \%$ \\
\hline Providencia & 1,487 & 0.371097687 & 2 & $3 \%$ & $1 \%$ & $53 \%$ & $19 \%$ & $34 \%$ & $41 \%$ \\
\hline San Cristobal & 744 & 0.611188669 & 1 & $11 \%$ & $46 \%$ & $27 \%$ & $35 \%$ & $31 \%$ & $61 \%$ \\
\hline $\begin{array}{l}\text { San Francisco } \\
\text { del Yeso }\end{array}$ & 738 & 0.443565319 & 2 & $22 \%$ & $22 \%$ & $53 \%$ & $32 \%$ & $30 \%$ & $33 \%$ \\
\hline San Jerónimo & 951 & 0.708907482 & 1 & $25 \%$ & $71 \%$ & $66 \%$ & $26 \%$ & $29 \%$ & $56 \%$ \\
\hline $\begin{array}{l}\text { San Juan de } \\
\text { Lopecancha }\end{array}$ & 569 & 0.752201859 & 1 & $18 \%$ & $26 \%$ & $90 \%$ & $22 \%$ & $34 \%$ & $66 \%$ \\
\hline Santa Catalina & 1,630 & 0.648497146 & 1 & $28 \%$ & $0 \%$ & $73 \%$ & $27 \%$ & $36 \%$ & $51 \%$ \\
\hline Santo Tomás & 4,008 & 0.484636478 & 2 & $18 \%$ & $15 \%$ & $67 \%$ & $19 \%$ & $32 \%$ & $45 \%$ \\
\hline Tingo & 1,202 & 0.466856128 & 2 & $17 \%$ & $22 \%$ & $57 \%$ & $18 \%$ & $33 \%$ & $45 \%$ \\
\hline Trita & 1,392 & 0.67436809 & 1 & $9 \%$ & $11 \%$ & $100 \%$ & $32 \%$ & $33 \%$ & $48 \%$ \\
\hline
\end{tabular}

a/ Es un valor entre 0 y 1 . Este índice es obtenido mediante el análisis factorial por el método de las componentes principales.

b/ Quintiles ponderados por la población, donde el 1=Más pobre y el 5=Menos pobre.

Fuente: Foncodes.

Elaboración propia. 
Cuadro N. ${ }^{\circ}$ 7. Departamento de Amazonas: capacidad instalada de los establecimientos de hospedaje colectivos y privado, 2007.

\begin{tabular}{|c|c|c|c|}
\hline \multirow{2}{*}{ Clasificación } & \multicolumn{2}{|c|}{ Capacidad } & \multirow{2}{*}{$\begin{array}{l}\text { \% de Amazonas con } \\
\text { respecto al total }\end{array}$} \\
\hline & Perú & Amazonas & \\
\hline \multicolumn{4}{|l|}{ Total } \\
\hline $\mathrm{N}^{\mathrm{o}}$ de establecimientos & 9,545 & 125 & 1.31 \\
\hline $\mathrm{N}^{\mathrm{o}}$ de habitaciones & 140,590 & 1,634 & 1.16 \\
\hline $\mathrm{N}^{\mathrm{o}}$ de plazas cama & 245,967 & 2,509 & 1.02 \\
\hline \multicolumn{4}{|l|}{ Clasificados } \\
\hline $\mathrm{N}^{\mathrm{o}}$ de establecimientos & 1,694 & 24 & 1.42 \\
\hline $\mathrm{N}^{\mathrm{o}}$ de habitaciones & 41,288 & 502 & 1.22 \\
\hline $\mathrm{N}^{\mathrm{o}}$ de plazas cama & 76,295 & 755 & 0.99 \\
\hline \multicolumn{4}{|l|}{ No clasificados } \\
\hline $\mathrm{N}^{\mathrm{o}}$ de establecimientos & 7,851 & 101 & 1.29 \\
\hline $\mathrm{N}^{\mathrm{o}}$ de habitaciones & 99,302 & 1,132 & 1.14 \\
\hline $\mathrm{N}^{\mathrm{o}}$ de plazas cama & 169,672 & 1,754 & 1.03 \\
\hline
\end{tabular}

Fuente: Ministerio de Comercio Exterior y Turismo.

Elaboración propia.

Cuadro N..$^{\circ}$. Departamento de Amazonas: capacidad ofertada de los establecimientos de alojamiento colectivo no clasificados, enero 2007.

\begin{tabular}{|c|c|c|c|}
\hline \multirow{2}{*}{ Clasificación } & \multicolumn{2}{|c|}{ Capacidad } & \multirow{2}{*}{$\begin{array}{l}\text { \% de Amazonas con } \\
\text { respecto al total }\end{array}$} \\
\hline & Perú & Amazonas & \\
\hline \multicolumn{4}{|l|}{ Total } \\
\hline $\mathrm{N}^{\mathrm{o}}$ de establecimientos & 7,826 & 101 & 1.29 \\
\hline $\mathrm{N}^{\mathrm{o}}$ de habitaciones & 99,386 & 1,132 & 1.14 \\
\hline $\mathrm{N}^{\mathrm{o}}$ de plazas cama & 169,868 & 1,754 & 1.03 \\
\hline \multicolumn{4}{|l|}{ Hasta 5 habitaciones } \\
\hline $\mathrm{N}^{\mathrm{o}}$ de establecimientos & 1,822 & 32 & 1.76 \\
\hline $\mathrm{N}^{\mathrm{o}}$ de habitaciones & 1,365 & 51 & 3.74 \\
\hline $\mathrm{N}^{\mathrm{o}}$ de plazas cama & 2,992 & 103 & 3.44 \\
\hline \multicolumn{4}{|l|}{ Con 6 a 12 habitaciones } \\
\hline $\mathrm{N}^{\mathrm{o}}$ de establecimientos & 2,864 & 28 & 0.98 \\
\hline $\mathrm{N}^{\mathrm{o}}$ de habitaciones & 25,474 & 248 & 0.97 \\
\hline $\mathrm{N}^{\mathrm{o}}$ de plazas cama & 43,346 & 413 & 0.95 \\
\hline
\end{tabular}




\begin{tabular}{|c|c|c|c|}
\hline \multirow{2}{*}{ Clasificación } & \multicolumn{2}{|c|}{ Capacidad } & \multirow{2}{*}{$\begin{array}{l}\text { \% de Amazonas con } \\
\text { respecto al total }\end{array}$} \\
\hline & Perú & Amazonas & \\
\hline \multicolumn{4}{|c|}{ Con 13 a 19 habitaciones } \\
\hline $\mathrm{N}^{\mathrm{o}}$ de establecimientos & 1,591 & 23 & 1.45 \\
\hline $\mathrm{N}^{\mathrm{o}}$ de habitaciones & 24,949 & 362 & 1.45 \\
\hline $\mathrm{N}^{\mathrm{o}}$ de plazas cama & 41,176 & 576 & 1.40 \\
\hline \multicolumn{4}{|c|}{ Con 20 a 29 habitaciones } \\
\hline $\mathrm{N}^{\circ}$ de establecimientos & 954 & 12 & 1.26 \\
\hline $\mathrm{N}^{\mathrm{o}}$ de habitaciones & 22,259 & 269 & 1.21 \\
\hline $\mathrm{N}^{\mathrm{o}}$ de plazas cama & 38,058 & 370 & 0.97 \\
\hline \multicolumn{4}{|c|}{ Con 30 a 49 habitaciones } \\
\hline $\mathrm{N}^{\mathrm{o}}$ de establecimientos & 487 & 6 & 1.23 \\
\hline $\mathrm{N}^{\mathrm{o}}$ de habitaciones & 17,724 & 202 & 1.14 \\
\hline $\mathrm{N}^{\circ}$ de plazas cama & 30,244 & 292 & 0.97 \\
\hline \multicolumn{4}{|c|}{ Con 50 a más habitaciones } \\
\hline $\mathrm{N}^{\mathrm{o}}$ de establecimientos & 108 & 0 & 0.00 \\
\hline $\mathrm{N}^{\mathrm{o}}$ de habitaciones & 7,615 & 0 & 0.00 \\
\hline $\mathrm{N}^{0}$ de plazas cama & 14,052 & 0 & 0.00 \\
\hline
\end{tabular}

Fuente: Ministerio de Comercio Exterior y Turismo.

Elaboración propia.

\section{Bibliografía}

BALLART HERNÁNDEZ, J y TRESSERRAS, Juan

2001 Gestión del patrimonio cultural. Barcelona: Ariel.

BRUSH, Stephen B.

1977 Mountain, field and family: the economy and human ecology and andean valley. Pennsylvania: University of Pennsylvania Press.

GATES CHÁVEZ, Carlos

1997 La historia inédita de los chachapoyas. Lima: Universidad San Martín de Porres. JURDAO, Francisco

1979 España en venta: compra de suelos por extranjeros y colonización de campesinos en la Costa del Sol. Madrid: Ayuso.

LABARTA GAVIRIA, Mario

1974 España a go-go: turismo charter y neocolonialismo del espacio. Madrid: Turner. MUNICIPIO DISTRITAL DE MARÍA

2006 Recuperación de la arquitectura tradicional y turística del distrito de María. Lima: Estudio de pre-inversión.

NARVÁEZ BAZAN, Javier

2001 El marketing del producto Kuelap. Tesis de Magíster en Administración de Negocios. Lima: CENTRUM-PUCP.

PLASENCIA, Rommel

2007 "Turismo y re-creación étnica en la selva peruana". En: Investigaciones Sociales 18:402-420. Lima: Universidad Nacional Mayor de San Marcos. 
REVENTÓS GIL, Ana

2007 "Patrimonios incómodos para la imagen que Barcelona ofrece al mundo". En: Pasos, Revista de Turismo y Patrimonio (5), 3. Tenerife: Universidad de La Laguna.

SCHJELLERUP, Inge R.

2005 Incas y españoles en la conquista de los chachapoya. Lima: PUCP/IFEA.

SMITH, Valene (ed.)

1992 Anfitriones e invitados. Madrid: Endymión.

SHELLER Mimi (ed.)

2002 Consuming the Caribbean. Londres: Routledge.

TRUJILLO YOSHISATO, María

2003 Estudio etnobotánico del anexo de Kuelap. Tesis de Ing. Forestal. Lima: Universidad Nacional Agraria de La Molina.

URRY, John

2004 La mirada del turista. Lima: Universidad San Martín de Porres. 